九州大学学術情報リポジトリ

Kyushu University Institutional Repository

\title{
Properties of MDF Panels Manufactured With foam-type UF ResinAdhesive
}

Wen, Ming-Yu

Department of Housing Environmental Design, and Research Institute of Human Ecology, College of Human Ecology, Chonbuk National University

Park, Hee-Jun

Department of Housing Environmental Design, and Research Institute of Human Ecology, College of Human Ecology, Chonbuk National University

Oh, Seung-Won

Department of Wood Science and Technology, College of Agriculture and Life Science, Chonbuk National University

Kang, Chun-Won

Department of Housing Environmental Design, and Research Institute of Human Ecology, College of Human Ecology, Chonbuk National University

他

https://doi.org/10.5109/1434402

出版情報：九州大学大学院農学研究院紀要. 59 (1)，pp. 133-136，2014-02-28. Faculty of Agriculture, Kyushu University

バージョン :

権利関係 : 


\title{
Properties of MDF Panels Manufactured With foam-type UF ResinAdhesive
}

\author{
Ming-Yu WEN ${ }^{1}$, Hee-Jun PARK ${ }^{*}$, Seung-Won OH $^{2}$, Chun-Won KANG ${ }^{1}$, \\ Jung-Woo HWANG ${ }^{2}$ and Junji MATSUMURA ${ }^{3}$ \\ Laboratory of Wood Science, Division of Sustainable Bioresources Science, \\ Department of Agro-environmental Sciences, Faculty of Agriculture, \\ Kyushu University, Fukuoka 812-8581, Japan \\ (Received October 31, 2013 and accepted November 19, 2013)
}

\begin{abstract}
The mechanical properties, dimensional stability, and sound absorption ability of MDF panels manufactured with developed foam-type urea-Formaldehyde (UF) resin adhesives were investigated. The cure characteristics of resins were determined by differential scanning calorimetry analysis (DSC), and the reined fibers and the porosity of the MDF panel were observed by SEM. MDF panels prepared with A foam-type UF resin had better mechanical properties and dimensional stability, even better than control MDF panels. However, there was no significant difference in sound absorption ability among panels. DSC analysis revealed that A foam-type UF had a lower onset and peak temperature and a slightly sharper peak curve. In addition, it was observed by SEM that much more A foam-type UF resin adhesive agglomerated on the fiber surface, exhibiting better foaming effect, and that the porosity of the MDF panel was reduced, further confirming the foam effect.
\end{abstract}

Key words: MDF panels, foam-type UF resin, mechanical property, dimensional stability, sound absorption, porosity

\section{INTRODUCTION}

Medium-density fiberboard (MDF) is an important composite material that is extensively used in furniture manufacturing, interior decorating. Light weight MDF can satisfy more application because of porous structure and low potential for swelling, which provide good thermal and sound insulation properties and good dimensional stability. It is well known that the properties of MDF panels generally depend on the characteristics of the resin and the fibers as well as the process of bonding. Usually, $\mathrm{MDF}$ is manufactured using urea-formaldehyde (UF) resin to bind the wood fibers together. Thus, the degree of resin curing contributes to the properties of woodbased composites bonded by UF resin.

Many studies have been devoted to investigate the contributions of various factors to MDF properties, including resin curing rate, catalyst content, fiber refining conditions, wood chemical characteristics, fiber treatment, and the hot-pressing process 2, 3. Y. Bai et al. (2011) found that MDF made with ambient-aged fibers had poorer mechanical properties than MDF made with fresh fibers, indicating poorer wettability of UF resin due to the decreased surface energy after aging. Some researchers have studied lightweight MDF panels made with an iso-

\footnotetext{
Department of Housing Environmental Design, and Research Institute of Human Ecology, College of Human Ecology, Chonbuk National University, Jeonju 561-756, Korea

Department of Wood Science and Technology, College of Agriculture and Life Science, Chonbuk National University, Jeonju 561-756, Korea

Laboratory of Wood Science, Division of Sustainable Bioresources Science, Department of Agro-environmental Sciences, Faculty of Agriculture, Kyushu University, Fukuoka 812-8581, Japan

* Corresponding author (E-mail: phjun@jbnu.ac.kr)
}

cyanate compound resin adhesive and discussed the effect of isocyanate resin type, resin content, and fiber type on the fundamental board properties 5. J. Xu et al (2003) prepared low-density binderless particleboard from kenaf core.

However, currently, information available on MDF panels prepared using foam-type UF resin adhesive is limited. During hot processing, gas produced by chemical reactions of the foam-type UF resin, which provided foams that increase the adhesion volume and the contact among fibers, and reduced the porosity in lightly compact board. Therefore, the objective of the current study was to investigate the properties of MDF panels prepared with developed foam-type UF resin adhesives and to generate useful information to optimize the foam-type UF resin for applications for light weight panels for decorative and nonstructural use with non-wood residues such as Miscanthus straw.

\section{MATERIALS AND METHODS}

\section{Foam-type UF resin preparation}

Commercial wood fiber and UF resin (E1 grade, which has $58 \%$ solid content and pH of 7.85 ) were used. The foam- type UF resins were prepared by mixing three kinds of foaming agent with UF resin. The main components of A foaming agent were sodium bicarbonate $\left(\mathrm{NaHCO}_{3}\right)$ and ammonium chloride $\left(\mathrm{NH}_{4} \mathrm{Cl}\right)$. And ammonium bicarbonate $\left(\mathrm{NH}_{4} \mathrm{HCO}_{3}\right)$, ammonium chloride $\left(\mathrm{NH}_{4} \mathrm{Cl}\right)$ and iron trioxide were the main components for $\mathrm{B}$ and $\mathrm{C}$ foaming agent. These components were mixed at fixed proportion and then added into UF resin. In term of the control UF resin, $0.5 \% \mathrm{NH}_{4} \mathrm{Cl}$ was added based on the liquid UF resin. The graph of UF resin before and after foaming is shown in Fig. 1. 

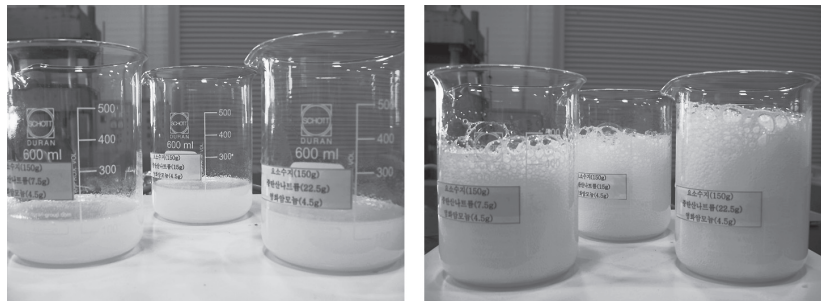

Fig. 1. UF resin before and after foaming.

\section{Preparation of MDF panels}

The dimension of panels was $300 \times 300 \times 10 \mathrm{~mm}$ with a target density of $0.6 \mathrm{~g} / \mathrm{cm}^{3}$. The resin content of all panels was $7 \%$ based on the solid resin of the oven-dried fiber. After resin spray, resined fiber loosening and mat foaming, the mats were hot pressed at $150^{\circ} \mathrm{C}$ for $10 \mathrm{~min}$ in three steps, 3.9 MPa for $5 \mathrm{~min}, 2.9 \mathrm{MPa}$ for $3 \mathrm{~min}$ and $1.9 \mathrm{MPa}$ for $2 \mathrm{~min}$. Three panels each were prepared with the different UF adhesives. The MDF panel prepared with control UF resin was defined as control MDF, and that prepared with $\mathrm{A}, \mathrm{B}$ and $\mathrm{C}$ foam-type resin adhesives were defined as A-, B- and C-MDF panel respectively.

\section{Evaluation of panel properties}

All panels were cut into specimens including 8 pecimens for each density, moisture content, internal bond, and modulus of rupture. The physical and mechanical tests were carried out in accordance with Korean standard KS F 3200-2006. All specimens were conditioned at $60 \% \mathrm{RH}$ and $20^{\circ} \mathrm{C}$ for 3 weeks. The internal bond strength (IB) and thickness swelling (TS) tests were performed at a size of $50 \mathrm{~mm} \times 50 \mathrm{~mm} \times 10 \mathrm{~mm}$, and for the modulus of rupture (MOR) tests with the size of $240 \mathrm{~mm} \times 50 \mathrm{~mm} \times$ $10 \mathrm{~mm}$.

\section{Differential Scanning Calorimetry (DSC) Analysis}

UF samples were prepared by the mixture of UF resin with foam agents and $\mathrm{NH}_{4} \mathrm{Cl}$ catalyst homogeneously according to the designated ratio. The prepared samples (about $8 \mathrm{mg}$ ) were placed high pressure cells. DSC analysis was conducted by DSC (TA Q10, USA) at a heating rate of $5^{\circ} \mathrm{C} / \mathrm{min}$ from 20 to $200^{\circ} \mathrm{C}$.

\section{Scanning Electron Microscopy (SEM) analysis}

The surfaces of the MDF panels were scanned by SEM (S-3000N) to obtain the porosity graph. Among the eight specimens after internal bond strength (IB) testing, the one that had values of IB strength and density closest to the average of the panels was selected, then an appropriate piece was taken away from the fractured layer for SEM scanning to obtain a micrograph of resined fiber.

\section{Sound absorption test}

Specimens $29 \mathrm{~mm}$ in diameter were mill cut from each MDF panel and underwent sound absorption testing according to ASTM E-1050 by transfer function method. The method is based on the frequency response function between the two sound pressure signals as measured by two microphones placed along the tube wall 7 . The estimation frequency range was from 500 to $6400 \mathrm{~Hz}$. The test was conducted at $1003.5 \mathrm{hPa}, 25^{\circ} \mathrm{C}, 50 \%, 346.15$ $\mathrm{m} / \mathrm{s}, 1.177 \mathrm{~kg} / \mathrm{m}^{3}$ and $405.2 \mathrm{~Pa} /(\mathrm{m} / \mathrm{s})$ for pressure, temperature, relative humidity, sound velocity, air density and characteristic acoustic impedance respectively. Four replication tests were conducted.

\section{RESULTS AND DISCUSSION}

\section{Mechanical properties}

For IB strength, as shown in Fig. 2, good results were obtained from the control MDF panel and the A-MDF panel, especially $0.45 \mathrm{MPa}$ for A-MDF panels, which exhibited a relatively high IB performance. This high bonding strength may be contributed to well foamed UF resin during hot pressing which resulted in more bonding points and increased contact among fibers, as well as to the better curing in the DSC analysis described. An inter-fiber bond was created by the absorption and interlocking of UF resin and fiber surfaces. However, the IB strength of B-MDF and C-MDF were too poor to satisfy the requirement. The variation in the mechanical properties of MDF panels was considered to relate to the difference between foam-type UF resins.

\section{Dimensional stability}

The results of thickness swelling (TS) and water absorption (WA) tests are shown in Fig. 2. Generally, the lower-density fiberboards had a lower degree of TS, as less spring-back occurred with low a compaction ratio. With $0.6 \mathrm{~g} / \mathrm{cm}^{3}$ density, the A-MDF panel exhibited better dimensional stability that was 50\% higher than that of control MDF panel, indicating the achievement of satisfactory inter-fiber bonding. This also suggested that the foaming process did not influence the bonding ability of UF resin, which was also confirmed by better IB

Table 1. Mechanical properties and dimensional stability of MDF panels

\begin{tabular}{lcccccr}
\hline Resin & MC (\%) & Density $\left(\mathrm{g} / \mathrm{cm}^{3}\right)$ & IB (MPa) & MOR (MPa) & TS (\%) & WA (\%) \\
\hline Control & $7.53(0.76)$ & $0.61(0.02)$ & $0.43(0.05)$ & $27.8(1.63)$ & $29.38(0.78)$ & $85.25(4.81)$ \\
A-type & $7.42(0.85)$ & $0.63(0.02)$ & $0.45(0.02)$ & $25.6(1.00)$ & $14.28(0.46)$ & $43.08(0.95)$ \\
B-type & $8.03(0.29)$ & $0.59(0.03)$ & $0.13(0.03)$ & $17.8(2.80)$ & $27.40(0.48)$ & $147.99(2.56)$ \\
C-type & $8.21(0.54)$ & $0.61(0.03)$ & $0.11(0.04)$ & $12.6(3.07)$ & $28.00(1.89)$ & $154.46(2.93)$ \\
\hline
\end{tabular}

Note: 1) MC, moisture content; IB, internal bond strength; MOR, modulus of rupture; TS, thickness swelling; WA, water absorption

2) The values in the parentheses are the standard deviations. 


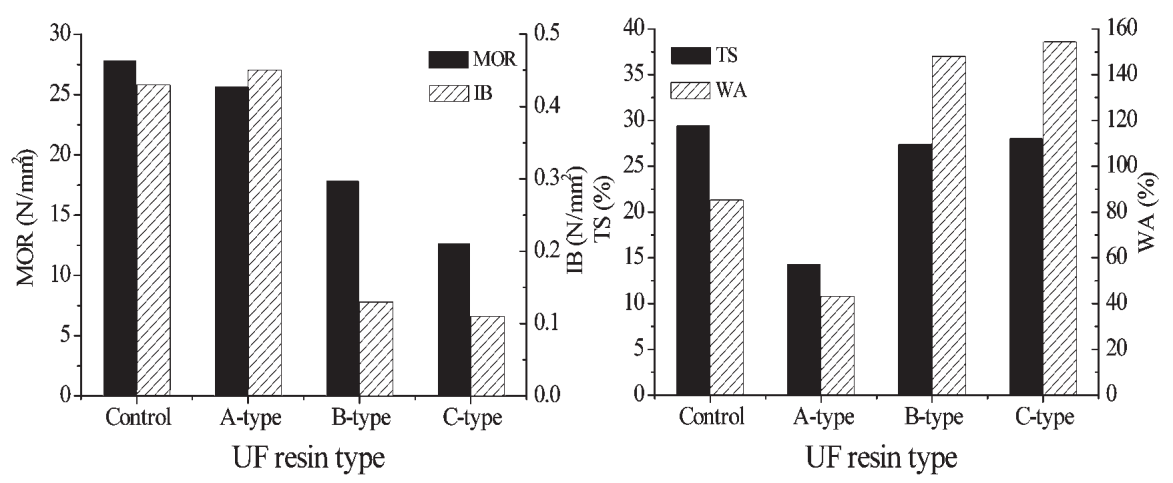

Fig. 2. MOR, IB, TS and WA of MDF panels related to UF resin type.

strength. Whereas, the WA performances of the B-MDF and $\mathrm{C}-\mathrm{MDF}$ panels were much inferior to the performance of the control MDF panel. Dimensional stability is strongly related to bonding ability. It is considered that their foaming reaction was unfavorable to the curing, thus both the water resistance and the bonding ability of the UF resin were reduced.

\section{UF resin curing by DSC analysis}

It is well known that the degree of resin curing contributes to the properties of panels bonded by UF resin8, 9. A high curing degree should be ensured to optimize the properties of the panels. With the addition of foaming agent, the curing of foam-type UF resin was supposed to differ from the UF resin. Therefore, DSC was applied to investigate the curing behavior. The DSC cures of each UF resins were illustrated in Fig. 3. The onset temperature (Ts) is an indicator of UF cure or reactivity, the peak temperature ( $\mathrm{Tp}$ ) is an important parameter of comparing the reactivity of resin. At the heating rate of $5^{\circ} \mathrm{C} / \mathrm{min}$, the control UF resin showed an Ts of $84.02^{\circ} \mathrm{C}$ and a $\mathrm{Tp}$ of $101.5^{\circ} \mathrm{C}$. However, lower Ts and Tp temperature $\left(81.16^{\circ} \mathrm{C}\right.$ and $\left.96^{\circ} \mathrm{C}\right)$ were observed for A foam-type UF resin. A foam-type resin also exhibited a taller and narrower temperature peaks, implying that the resin cured more completely. Lower Ts make cure fast in the early stage. Consequently, it is believed that A foaming reaction was not only well occurred, but also it accelerated the curing reaction, resulting in better bonding ability during the hot press process. For B and C foam-type $\mathrm{UF}$, Ts is $86.22^{\circ} \mathrm{C}$ and $87.27^{\circ} \mathrm{C}$ higher than the control $\mathrm{UF}$, and the Tp is similar to the control UF.

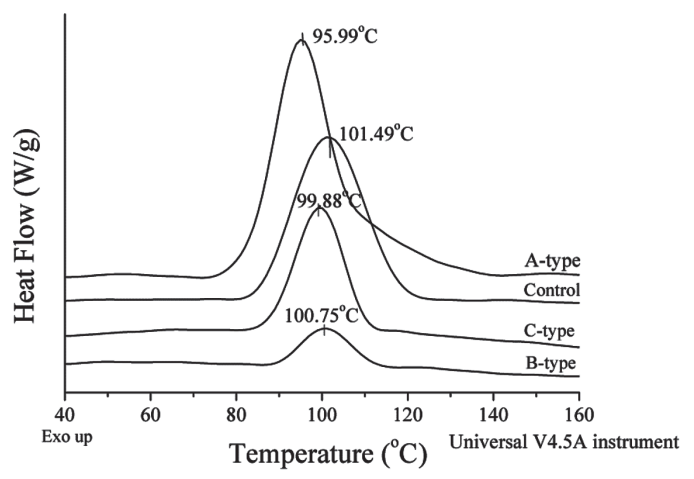

Fig. 3. DSC curves of control UF resin and foam-type UF resins.

\section{SEM micrographs of resined fibers and MDF panel}

The SEM technique was used to observe the distribution of resins on the fiber surface. It revealed that the resin was uniformly distributed on the fiber surface. Particularly for A-MDF, resin agglomerated on the fiber surface even as a covering and fiber bundle were formed, implying that A-type foam UF resin had a better foaming effect, which resulted in better mechanical properties. Because of better bonding, breakage of bonded fibers led to cohesive failures of the fiber as shown in the Fig. 4 A-type SEM micrograph. This indicates that the cohesive strength of cured resin and the resined fiber interface were higher. However, compared with control MDF and $\mathrm{A}-\mathrm{MDF}$, in the B and C-MDF, breakage mostly occurred on the resin-fiber interfaces, with almost no cohesive failures of the fibers. Consequently, poor bonding strength resulted as stated above.

Moreover, the porosity of the MDF panels were also observed by SEM. Porosity of $26.40 \%$ and $16.75 \%$ were calculated for the control MDF and A-MDF panels respectively. As shown in Fig. 5, control MDF panels exhibited different porosity types, whereas A-MDF shows rela-
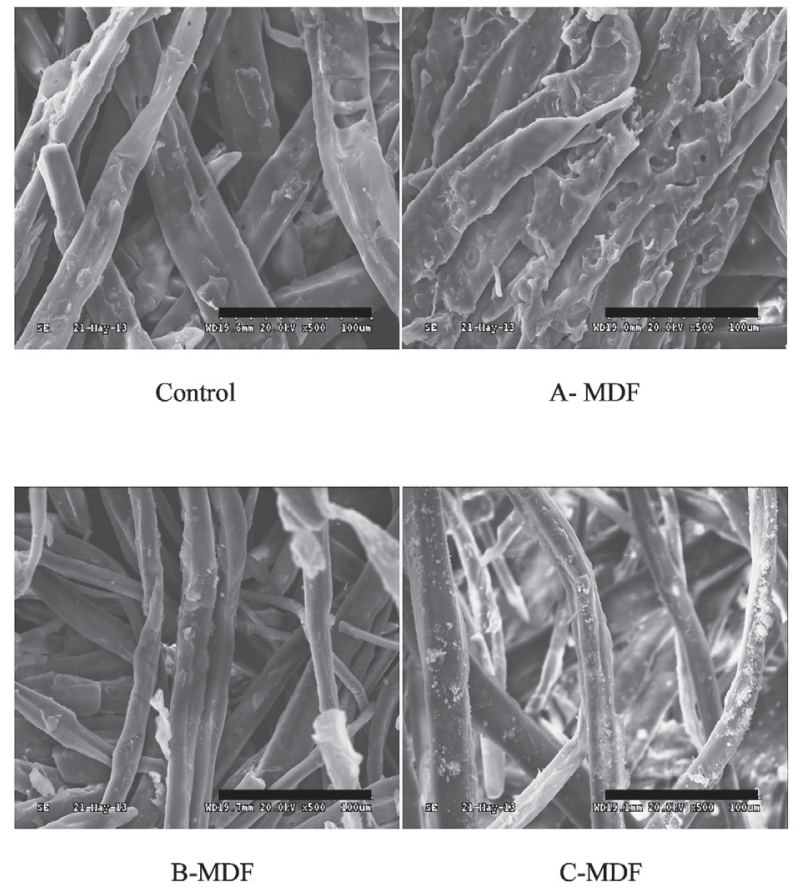

Fig. 4. SEM micrographs of resined fibers (scale bar $=100 \mu \mathrm{m}$ ). 
tively compact surface which confirms that the A foamtype UF resin was well foamed during hot pressing and the foamed resin filled some pores, which would be favorable for light weight board.

\section{Sound absorption capability of MDF panels}

The sound absorption coefficients of MDF panels were measured by a transfer function method using an impedance tube. Sound absorption ability was highly dependent on the sound frequency, board density and board thickness (10 $\mathrm{mm}$ in this study). Fig. 6 shows that as porous material all samples presented increase tendency with the increase of frequency. The tendency of A-MDF panel was most similar to that of control, even though the porosity decreased by $36.55 \%$. The average of sound absorption coefficient at 250, 500, 1000, and $2000 \mathrm{~Hz}$ (defined as NCR) was calculated for each sample. And $0.073,0.077,0.061$ and 0.082 were obtained for control, A-, B- and C-MDF. Overall, there was not a pronounced difference in the sound absorption coefficient among the samples, indicating that use of foam-type UF resin has little effect on the sound absorption ability of MDF panels. It is supposed that for a density of $0.6 \mathrm{~g} / \mathrm{cm}^{3}$, a relatively higher density, the influence of foamed adhesive on the sound absorption ability was limited. Therefore, to get more information further study should be carried out on the lighter weight MDF or wood-based boards.

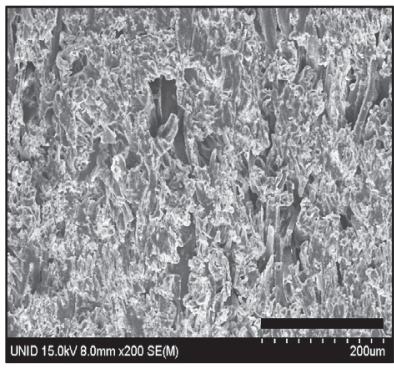

Control MDF

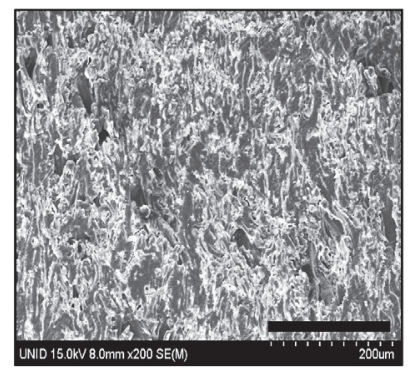

A-MDF
Fig. 5. Porosity micrograph of MDF panels (scale bar=100 $\mu \mathrm{m}$ )

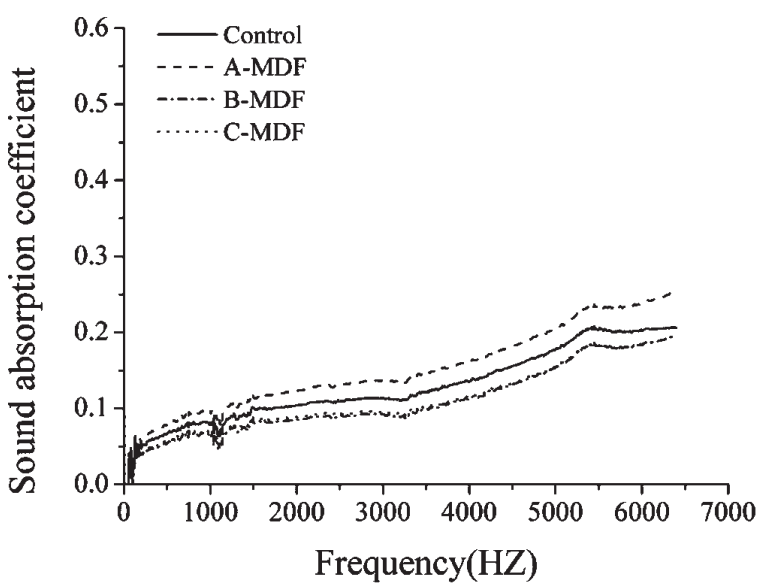

Fig. 6. Frequency versus sound absorption coefficients of MDF panels.

\section{CONCLUSION}

The MDF made with A-foam-type UF resin showed good mechanical properties and dimensional stability. However, there was no significant variation in sound absorption ability at a density of $0.6 \mathrm{~g} / \mathrm{cm}^{3}$. DSC analysis found that A-foam-type UF resin with lower peak temperature cured more completely, suggesting that the foaming agent was favorable for curing. SEM observation confirmed that A-foam-type UF resin was well foamed and distributed on the fiber surface, and that the panel porosity was reduced. Therefore, A foam-type UF resin was recommended for manufacturing wood panels. The results of this study may be attributed to apply foamtype UF resin to make light weight wood-based panels with non-wood residues such as Miscanthus straw. These panels should be suitable for ceiling boards and interior decorating. Further study of light weight panels is ongoing.

\section{ACKNOWLEDGMENT}

The present work is supported by the research fund of the Rural Development Administration, Korea (PJ007964).

\section{REFERENCES}

Dunky, M. 1998 Urea-formaldehyde (UF) adhesive resins for wood. Int $J$ Adhes Adhes 18: 95-107

Garcia, R. A., A. Cloutier and B. Riedl 2006 Chemical modification and wetting of medium density fibreboard panels produced from fibres treated with maleated polypropylene wax. Wood Sci Technol 40: 402-416

Xu, J., G. Han, E. D. Wong and S. Kawai 2003 Development of binderless particleboard from kenaf core using steam-injection pressing. J Wood Sci 48: 327-332

Bai, Y. and Z. Gao 2011 The ambient aging of wood fiber and its effect on mechanical properties of MDF panels. Wood Sci Technol. 45: 501-510

Kawasaki, T., M. Zhang and S. Kawai 1998 Manufacture and properties of ultra-low-density fiberboard. J Wood Sci. 44: 354360

Xu, J., R. Sugawara, R. Widyorini, G. Han and S. Kawai 2004 Manufacture and properties of low-density binderless particleboard from kenaf core. J Wood Sci. 50: 62-67

Kang, C. W., S. W. Oh, T. B. Lee, W. Kang and J. Matsumra 2012 Sound absorption capability and mechanical properties of a composite rice hull and sawdust board. J Wood Sci. 58: 273278

Xing, C., J. Deng, S. Y. Zhang, B. Riedl and A. Cloutier 2005 Differential scanning calorimetry characterizationof urea-formaldehyde resin curing behavior as affected by less desirable wood material and catalyst content. J Appl Polym Sci 98 2027-2032

Gao, Z.H., X. Y. Wang, H. Wang, and Y. Liu 2008 Curing characteristics of urea-formaldehyde resin in the presence of various amounts of wood extracts and catalysts. J Appl Polym Sci 107: $1555-1562$ 